ppi $201502 Z U 4645$

Esta publicación científica en formato digital es continuidad de la revista impresa ISSN-Versión Impresa 0798-1406 / ISSN-Versión on line 2542-3185Depósito legal pp $197402 Z$ U34

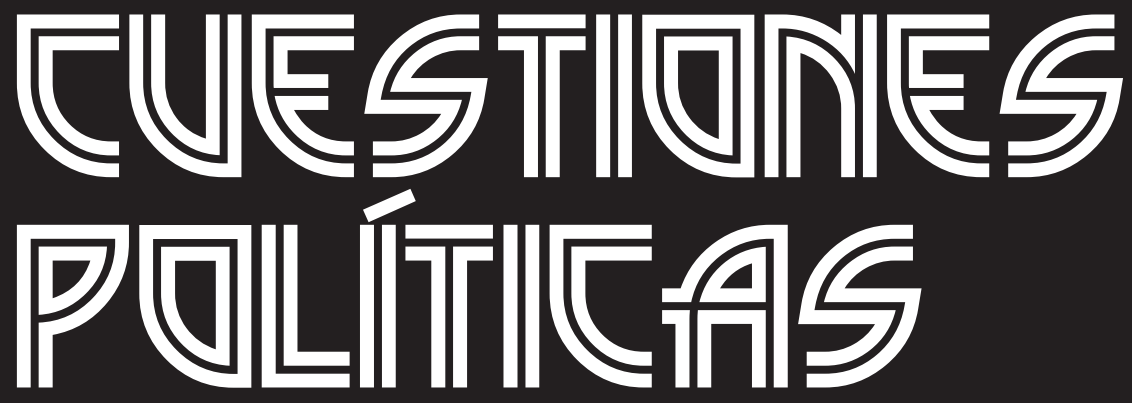

Instituto de Estudios Políticos y Derecho Público "Dr. Humberto J. La Roche" de la Facultad de Ciencias Jurídicas y Políticas de la Universidad del Zulia Maracaibo, Venezuela
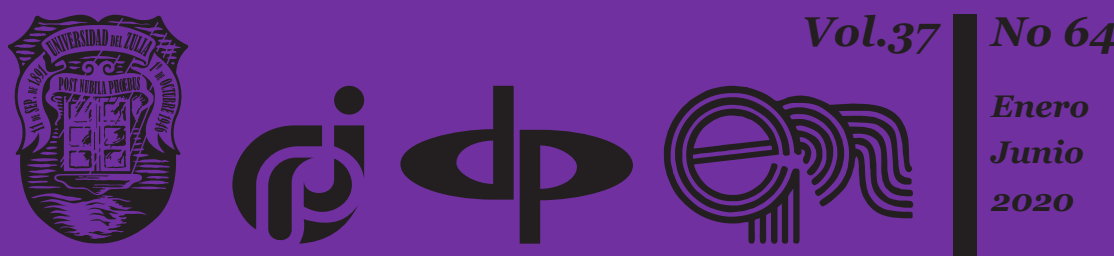


\title{
Reflexiones sobre el debido proceso en las Constituciones de América Latina
}

\author{
Edgar Germán Sánchez García *
}

\section{Resumen}

La investigación pretende analizar el debido proceso en las Constituciones de América Latina, concretamente en Ecuador, Venezuela, Colombia y Perú. El debido proceso es una constante en las Constituciones de algunos países pues su importancia rompe fronteras y se establece como una necesidad; por lo demás, las reflexiones contenidas en el manuscrito acerca de esta institución se hicieron con una metodología analítica, las fuentes principales fueron las Constituciones Nacionales de los países mencionados, además de jurisprudencia y opiniones doctrinales. La conclusión central es que existen parámetros internacionales acerca del debido proceso y, se asume, como un derecho humano fundamental que busca el respeto y la dignidad de las personas en cada etapa de las situaciones jurídicas que pudieran presentarse, encierra derechos, garantías y principios con trascendencia constitucional.

Palabras clave: debido proceso; constitución nacional; derechos humanos; derecho procesal; constitucionalismo en Latinoamérica.

1 * Abogado de los Juzgados y Tribunales de la República del Ecuador, Universidad Laica "Eloy Alfaro" (ULEAM) de Manabí, Ecuador; Especialista en Diseño Curricular por Competencia, Universidad "Del Mar” de Chile; Magister en Diseño y Evaluación de Modelos Educativos, Universidad Tecnológica Empresarial de Guayaquil (UTEG); doctorando en Ciencias Jurídicas, Universidad del Zulia, Venezuela. Email: germasaga@gmail.com. 


\title{
Reflections on due process in the Constitutions of Latin America
}

\begin{abstract}
The research aims to analyze due process in the Constitutions of Latin America, specifically in Ecuador, Venezuela, Colombia and Peru. Due process is a constant in the Constitutions of some countries because its importance breaks borders and is established as a necessity, the reflections contained in the manuscript about this institution were made with an analytical methodology, the main sources were the National Constitutions of the countries mentioned, in addition to jurisprudence and doctrinal opinions. The central conclusion is that there are international parameters about due process, and, it is assumed, as a fundamental human right that seeks the respect and dignity of people at each stage of legal situations that may arise, encloses rights, guarantees and principles with constitutional significance.
\end{abstract}

Keywords: due process; National Constitution; human rights; procedural law; constitutionalism in Latin America.

\section{Introducción}

Desde la perspectiva de los derechos humanos, a la persona le corresponde un cúmulo de prerrogativas por el hecho de ser persona sin ningún tipo de exigencia adicional. Por la correspondencia entre derecho y ser humano, el conjunto de derechos es amplísimo y resultarían cortas estas líneas para reflexionar acerca de ellos, por lo que el análisis se concentrará en el derecho al debido proceso elevado en las constituciones nacionales de Colombia, Ecuador, Perú y Venezuela. Se escogieron estos países para el análisis por sus referentes históricos en común además de las conexiones migratorias tradicionales que tienen, incluso por manejar, en gran medida, el mismo idioma. Resulta pertinente destacar que la metodología es analítica sin llegar a la comparación, por ello el objetivo del manuscrito es analizar el debido proceso en las Constituciones de América Latina, en los países que se mencionaron. El trabajo se divide en dos grandes acápites, el primero describe al debido proceso en normas internacionales y, el segundo, focalizado en cada una de las Constituciones Nacionales en referencia. 


\section{El debido proceso en las normas internacionales}

Como derecho humano, el debido proceso se encuentra planteado en diversos instrumentos jurídicos internacionales que resultan de gran relevancia para la consecución de éste y otros tantos derechos. "La adjetivación del proceso como debido permite que su devenir se eleve a derecho fundamental" (Prieto Monroy, 2003: 816). En este orden de ideas, la Organización de las Naciones Unidas (ONU) (s/a) ha dispuesto un amplio abanico de derechos aceptados internacionalmente, entre los que se encuentran derechos de carácter civil, cultural, económico, político y social. También se han establecido mecanismos para promover y proteger estos derechos y para ayudar a los Estados a ejercer sus responsabilidades. Del listado - para nosotros inacabado- de derechos humanos resalta el debido proceso.

La Declaración Universal de Derechos Humanos de la ONU (1948) establece en su artículo 8 el mencionado debido proceso indicando que: "Toda persona tiene derecho a un recurso efectivo ante los tribunales nacionales competentes, que la ampare contra actos que violen sus derechos fundamentales reconocidos por la constitución o por la ley”.

Este derecho también aparece contemplado por la Convención Americana sobre Derechos Humanos o Pacto de San José de Costa Rica (1969) en los artículos 7, 8, 9 y $25^{2}$, que plantean la libertad personal, las garantías judiciales, los principios de legalidad y de retroactividad, y la protección judicial.

“Artículo 7. Derecho a la Libertad Personal. 1. Toda persona tiene derecho a la libertad y a la seguridad personales. 2. Nadie puede ser privado de su libertad física, salvo por las causas y en las condiciones fijadas de antemano por las Constituciones Políticas de los Estados Partes o por las leyes dictadas conforme a ellas. 3. Nadie puede ser sometido a detención o encarcelamiento arbitrarios. 4. Toda persona detenida o retenida debe ser informada de las razones de su detención y notificada, sin demora, del cargo o cargos formulados contra ella. 5. Toda persona detenida o retenida debe ser llevada, sin demora, ante un juez u otro funcionario autorizado por la ley para ejercer funciones judiciales y tendrá derecho a ser juzgada dentro de un plazo razonable o a ser puesta en libertad, sin perjuicio de que continúe el proceso. Su libertad podrá estar condicionada a garantías que aseguren su comparecencia en el juicio. 6. Toda persona privada de libertad tiene derecho a recurrir ante un juez o tribunal competente, a fin de que éste decida, sin demora, sobre la legalidad de su arresto o detención y ordene su libertad si el arresto o la detención fueran ilegales. En los Estados Partes cuyas leyes prevén que toda persona que se viera amenazada de ser privada de su libertad tiene derecho a recurrir a un juez o tribunal competente a fin de que éste decida sobre la legalidad de tal amenaza, dicho recurso no puede ser restringido ni abolido. Los recursos podrán interponerse por sí o por otra persona. 7. Nadie será detenido por deudas. Este principio no limita los mandatos de autoridad judicial competente dictados por incumplimientos de deberes alimentarios.

Artículo 8. Garantías Judiciales. 1. Toda persona tiene derecho a ser oída, con las debidas garantías y dentro de un plazo razonable, por un juez o tribunal competente, independiente e imparcial, establecido con anterioridad por la ley, en la sustanciación de cualquier acusación penal formulada contra ella, o para la determinación de sus derechos y obligaciones de orden civil, laboral, fiscal o de cualquier otro carácter. 2. Toda persona inculpada de delito tiene derecho a que se presuma su inocencia mientras el traductor o intérprete, si no comprende o no habla el idioma del juzgado o tribunal; b) comunicación previa y detallada al inculpado de la acusación formulada; c) concesión al inculpado del tiempo y de los medios adecuados para la preparación de su defensa; d) derecho del inculpado de defenderse personalmente o de ser asistido por un defensor de su elección y de comunicarse libre y privadamente con su defensor; e) derecho irrenunciable de ser asistido por un defensor proporcionado por el Estado, 
A su vez, el Pacto Internacional de Derechos Civiles y Políticos (1966) lo establece en los artículos 2, 3 y 14; y, la Convención Americana sobre Derechos y Deberes del Hombre (1948) contempla al debido proceso como derecho a la justicia en su artículo XVIII, señalando lo siguiente:

Toda persona puede ocurrir a los tribunales para hacer valer sus derechos. Asimismo, debe disponer de un procedimiento sencillo y breve por el cual la justicia lo ampare contra actos de la autoridad que violen, en perjuicio suyo, alguno de los derechos fundamentales consagrados constitucionalmente.

Más allá de la denominación que se le otorgue, es conveniente destacar que lo imprescindible es el cumplimiento del debido proceso, pues no sólo está contemplado en normativas internacionales, sino que, más aún, está dirigido a la protección de las personas en cada proceso judicial o administrativo. Por lo anterior, ha sido recogido en la Carta Magna de varios países, de los que se destacarán a continuación Colombia, Ecuador, Perú y Venezuela.

\subsection{La Constitución Nacional y el debido proceso: El debido proceso en la Constitución de la República de Colombia}

En el caso colombiano, la Constitución Política de 1991 estatuye al debido proceso como un derecho fundamental, señalándolo en su artículo 29 de la siguiente manera:

El debido proceso se aplicará a toda clase de actuaciones judiciales y administrativas. Nadie podrá ser juzgado sino conforme a leyes preexistentes al acto que se le imputa, ante juez o tribunal competente y con observancia de la

remunerado o no según la legislación interna, si el inculpado no se defendiere por sí mismo ni nombrare defensor dentro del plazo establecido por la ley; f) derecho de la defensa de interrogar a los testigos presentes en el tribunal y de obtener la comparecencia, como testigos o peritos, de otras personas que puedan arrojar luz sobre los hechos; g) derecho a no ser obligado a declarar contra sí mismo ni a declararse culpable, y h) derecho de recurrir del fallo ante juez o tribunal superior. 3. La confesión del inculpado solamente es válida si es hecha sin coacción de ninguna naturaleza. 4. El inculpado absuelto por una sentencia firme no podrá ser sometido a nuevo juicio por los mismos hechos. 5. El proceso penal debe ser público, salvo en lo que sea necesario para preservar los intereses de la justicia.

Artículo 9. Principio de Legalidad y de Retroactividad. Nadie puede ser condenado por acciones u omisiones que en el momento de cometerse no fueran delictivos según el derecho aplicable. Tampoco se puede imponer pena más grave que la aplicable en el momento de la comisión del delito. Si con posterioridad a la comisión del delito la ley dispone la imposición de una pena más leve, el delincuente se beneficiará de ello (...)" (Organización de Estado Americanos, 1969. Paréntesis nuestros).

“Artículo 25. Protección Judicial. 1. Toda persona tiene derecho a un recurso sencillo y rápido o a cualquier otro recurso efectivo ante los jueces o tribunales competentes, que la ampare contra actos que violen sus derechos fundamentales reconocidos por la Constitución, la ley o la presente Convención, aun cuando tal violación sea cometida por personas que actúen en ejercicio de sus funciones oficiales. 2. Los Estados Partes se comprometen: a) a garantizar que la autoridad competente prevista por el sistema legal del Estado decidirá sobre los derechos de toda persona que interponga tal recurso; b) a desarrollar las posibilidades de recurso judicial, y c) a garantizar el cumplimiento, por las autoridades competentes, de toda decisión en que se haya estimado procedente el recurso" (Organización de Estados Americanos, 1969). 
plenitud de las formas propias de cada juicio. En materia penal, la ley permisiva o favorable, aun cuando sea posterior, se aplicará de preferencia a la restrictiva o desfavorable. Toda persona se presume inocente mientras no se la haya declarado judicialmente culpable. Quien sea sindicado tiene derecho a la defensa y a la asistencia de un abogado escogido por él, o de oficio, durante la investigación y el juzgamiento; a un debido proceso público sin dilaciones injustificadas; a presentar pruebas y a controvertir las que se alleguen en su contra; a impugnar la sentencia condenatoria, y a no ser juzgado dos veces por el mismo hecho. Es nula, de pleno derecho, la prueba obtenida con violación del debido proceso.

Por ello, se pueden extraer una serie de elementos que configuran partes relacionadas del debido proceso, en concreto la legalidad de las actuaciones, la congruencia de los fallos y lo planteado en juicio, la proporcionalidad entre aquello de lo que se acusa o imputa a la persona y la sanción a aplicar, el derecho a la defensa en concreto como oportunidad necesaria para rebatir los alegatos acusatorios, la presunción de inocencia, y el principio de non bis in ídem. Para enmarcar estos elementos, la Corte Constitucional de Colombia (2009) ha indicado que:

El debido proceso comporta al menos los derechos (i) a la jurisdicción, que a su vez conlleva las garantías a un acceso igualitario de los jueces, a obtener decisiones motivadas, a impugnar las decisiones ante autoridades de jerarquía superior y al cumplimiento de lo decidido en el fallo; (ii) al juez natural, identificado como el funcionario con capacidad legal para ejercer jurisdicción en determinado proceso o actuación, de acuerdo con la naturaleza de los hechos, la calidad de las personas y la división del trabajo establecida por la Constitución y la Ley; y (iii) el derecho a la defensa.

Cabe afirmar que tales elementos se aplican en todas las ramas del Derecho, pues se pretende obtener un proceso justo, expedito y transparente, sin vicios. "El debido proceso busca confirmar la legalidad y correcta aplicación de las leyes dentro de un marco de respeto mínimo a la dignidad humana” (Rodríguez Rescia, 1998: 328).

\subsection{El debido proceso en la Constitución de la República del Ecuador}

Para la República del Ecuador el debido proceso comprende una lista de garantías básicas a aplicar en todo proceso en el que se determinen derechos y obligaciones de cualquier orden, ello a tenor del artículo 76 constitucional del mencionado país. A grandes rasgos, entre las garantías se pueden mencionar las siguientes: la obligación de las autoridades de garantizar el cumplimiento de las normas y derechos de las partes, la presunción de inocencia hasta sentencia firme, la obligatoriedad de la tipicidad de las infracciones, faltas, delitos y su correspondiente sanción, el juez natural y la existencia previa del procedimiento correspondiente con la 
obtención de las pruebas de acuerdo a las disposiciones legales, el in dubio pro ciudadano o humano, la debida proporcionalidad entre la infracción y la sanción y el derecho a la defensa.

En este sentido, la Corte Constitucional de la República del Ecuador (2010: 6) ha definido al debido proceso como: "El conjunto de principios a observar en cualquier procedimiento, no solo como orientación sino como deber, destinado a garantizar de manera eficaz los derechos de las personas". De tal manera, que las garantías que engloba el debido proceso son de cumplimiento obligatorio, no son una mera referencia, sino que su objetivo es servir de soporte suficiente para cualquier proceso y en cada etapa del mismo.

\subsection{El debido proceso en la Constitución de la República del Perú}

En lo que respecta al Perú, establece, de manera sucinta, el debido proceso en el numeral $3^{\circ}$ del artículo 139 de su Carta Magna, en tal disposición indica como principios y derechos de la función jurisdiccional:

La observancia del debido proceso y la tutela jurisdiccional. Ninguna persona puede ser desviada de la jurisdicción predeterminada por la ley, ni sometida a procedimiento distinto de los previamente establecidos, ni juzgada por órganos jurisdiccionales de excepción ni por comisiones especiales creadas al efecto, cualquiera sea su denominación.

De ello se asume que, el término debido proceso en la Constitución de la República del Perú obedece a principios y derechos en relación al juez natural conforme a procedimiento previamente establecido en el ordenamiento jurídico, aplicable tanto a la vía administrativa como a la judicial. Ahora bien, los demás extremos del debido proceso contenidos en instrumentos internacionales no aparecen bajo tal denominación, pero igualmente se encuentran consagrados a nivel constitucional, en concreto, en el artículo 139 de la Constitución de la República del Perú.

\subsection{El debido proceso en la Constitución de la República Bolivariana de Venezuela}

En lo que respecta a la República Bolivariana de Venezuela, su Carta Magna establece en el artículo 49 que el debido proceso se aplicará a todas las actuaciones judiciales y administrativas, por ello expone una serie de prerrogativas que lo configuran y se encuentran interconectadas, a 


\section{0 \\ Edgar Germán Sánchez García \\ Reflexiones sobre el debido proceso en las Constituciones de América Latina}

saber: defensa y asistencia jurídica en cada fase del proceso con la debida notificación y acceso a las pruebas además del derecho a ser oída y a recurrir de las decisiones del tribunal u órgano administrativo; presunción de inocencia; el derecho al juez natural y la negativa de constituir tribunales ad hoc; también que ninguna persona podrá ser obligada a confesarse culpable o declarar contra sí misma, su cónyuge, concubino o concubina o pariente dentro del cuarto grado de consanguinidad y segundo de afinidad; la tipicidad de los delitos, faltas o infracciones; aunado a ello, ninguna persona podrá ser sometida a juicio por los mismos hechos en virtud de los cuales hubiese sido juzgada anteriormente, es decir la cosa juzgada; derecho a indemnizaciones por parte del Estado.

En el mismo orden de ideas, la Sala Constitucional del Tribunal Supremo de Justicia (2014) estableció que:

El debido proceso en el ordenamiento jurídico venezolano, constituye un derecho fundamental que comprende un conjunto de garantías sustanciales y procesales, especialmente diseñadas para asegurar la regularidad y eficacia de la actividad jurisdiccional y administrativa, cuando sea necesario definir situaciones controvertidas, declarar o aplicar el derecho en un caso concreto, o investigar y juzgar los hechos punibles.

De tal manera, que el debido proceso en Venezuela aparece como un derecho tanto en vía judicial como en vía administrativa, léase en cada mecanismo jurídico instaurado para resolver conflictos sociales.

\section{Conclusiones}

El debido proceso comporta una serie extensa de derechos, principios y garantías cuya particularidad central es que le pertenecen a la persona por el hecho de ser humano, por ello su campo de acción es amplísimo no solo por los países que lo recogen en sus respectivos ordenamientos jurídicos, sino que se encuentra plasmado en normas superiores, como son las Constituciones Nacionales. Además, obedecen a parámetros internacionales, tales como los contemplados por la Declaración Universal de Derechos Humanos, la Convención Americana sobre Derechos Humanos o Pacto de San José de Costa Rica, el Pacto Internacional de Derechos Civiles y Políticos, la Convención Americana sobre Derechos y Deberes del Hombre.

Cada país lo ha adecuado a sus exigencias, con planteamientos más o menos detallados, pero que sigue siendo debido proceso. Un debido proceso aplicable tanto a la vía administrativa como a la judicial. El debido proceso es, entonces, un derecho humano fundamental que busca el respeto y la dignidad de las personas en cada etapa de las situaciones jurídicas 
que pudieran presentarse, encierra derechos, garantías y principios con trascendencia constitucional.

\section{Referencias Bibliográficas}

ASAMBLEA NACIONAL CONSTITUYENTE CONSTITUCIÓN POLÍTICA DE COLOMBIA. 1991. Edición especial preparada por la Corte Constitucional, actualizada con los actos legislativos a 2015. Corte Constitucional. Consejo Superior de la Judicatura. Sala Administrativa. Centro de Documentación Judicial (CENDOJ). Bogotá, Colombia.

ASAMBLEA NACIONAL CONSTITUYENTE. 1999. Constitución de la República Bolivariana de Venezuela. Gaceta Oficial de la República de Venezuela número 36.860 Ordinario, de fecha 30 de diciembre de 1999. Reimpresa por error material del ente emisor. Gaceta Oficial de la República Bolivariana de Venezuela número 5.453 Extraordinario, de fecha 24 de marzo de 2000. Enmienda No. 1 de la Constitución de la República Bolivariana de Venezuela. Gaceta Oficial de la República Bolivariana de Venezuela número 5.908 Extraordinario, de fecha 19 de febrero de 2009. Caracas, Venezuela.

ASAMBLEA NACIONAL CONSTITUYENTE. 2008. Constitución Política de la República del Ecuador. Registro Oficial número 449, de fecha 20 de octubre de 2008. Quito, Ecuador.

CONGRESO CONSTITUYENTE DEMOCRÁTICO. 1993. Constitución Política del Perú. Décimo Tercera Edición Oficial del Ministerio de Justicia y Derecho Humanos. Texto actualizado con las reformas ratificadas en el Referéndum de 2018. Disponible en línea. En: https://www.minjus. gob.pe/wp-content/uploads/2019/05/Constitucion-Politica-delPeru-marzo-2019_WEB.pdf. Fecha de consulta 27/12/2019. Fecha de consulta: 15/12/2019.

CORTE CONSTITUCIONAL DE COLOMBIA. 2009. Demanda de inconstitucionalidad contra el artículo 314 (parcial) dela Ley 906 de 2004, modificado por el artículo 27 de la Ley 1142 de 2007, "por medio de la cual se reforman parcialmente las Leyes 906 de 2004, 599 de 2000 y 600 de 2000 y se adoptan medidas para la prevención y represión de la actividad delictiva de especial impacto para la convivencia y seguridad ciudadana". Sentencia C-163/19, de fecha 10-04-2019. Disponible en línea. En: https://www.corteconstitucional.gov.co/relatoria/2019/C-163-19.htm. Fecha de consulta: 15/12/2019. 
Edgar Germán Sánchez García
52 Reflexiones sobre el debido proceso en las Constituciones de América Latina

CORTE CONSTITUCIONAL DE LA REPÚBLICA DEL ECUADOR. 2010. Sentencia $\mathrm{N}^{\circ}$ 0004-10-SEP-CC. Caso $\mathrm{N}^{\circ}$ 0388-09-EP. Fecha 24-022010. Quito, Ecuador. P.p. 6.

ORGANIZACIÓN DE ESTADOS AMERICANOS. 1948. Convención Americana sobre Derechos y Deberes del Hombre. Disponible en línea. En: http:// www.oas.org/es/cidh/mandato/Basicos/declaracion.asp. Fecha de consulta: 15/12/2019.

ORGANIZACIÓN DE LAS NACIONES UNIDAS. 1948. La Declaración Universal de Derechos Humanos. Disponible en línea. En: https://www. un.org/es/universal-declaration-human-rights/. Fecha de consulta: 15/12/2019.

ORGANIZACIÓN DE LAS NACIONES UNIDAS. 1966. Pacto Internacional de Derechos Civiles y Políticos. Disponible en línea. En: https://www.ohchr. org/SP/ProfessionalInterest/Pages/CCPR.aspx. Fecha de consulta: 15/12/2019.

ORGANIZACIÓN DE LAS NACIONES UNIDAS. s/a. ¿Qué son los derechos humanos? Disponible en línea. En: https://www.un.org/es/sections/ issues-depth/human-rights/index.html. Fecha de consulta: 15/12/2019.

ORGANIZACIÓN DE LOS ESTADOS AMERICANOS. 1969. Convención Americana sobre Derechos Humanos o Pacto de San José de Costa Rica. Disponible en línea. En: https://www.oas.org/dil/esp/tratados_b-32_ convencion_americana_sobre_derechos_humanos.htm. Fecha de consulta: $27 / 12 / 2019$.

PRIETO MONROY, Carlos Adolfo. 2003. "El proceso y el debido proceso". En: Vniversitas. Número 106. Diciembre. Pontificia Universidad Javeriana. Colombia, Bogotá. Pp. 811-823.

RODRÍGUEZ RESCIA, Victor Manuel. 1998. "El debido proceso legal y la Convención Americana sobre Derechos Humanos" En: Revista de la Facultad de Ciencias Jurídicas y Políticas, número 110. Universidad Central de Venezuela. Caracas, Venezuela. Pp. 327-372.

TRIBUNAL SUPREMO DE JUSTICIA. Sala Constitucional. 2014. Sentencia 878, de fecha 22-07-2014. Disponible en línea. En: https://vlexvenezuela. com/vid/gwondeline-gonzalez-chirinos-593347686. Fecha de consulta: 27/12/2019. 

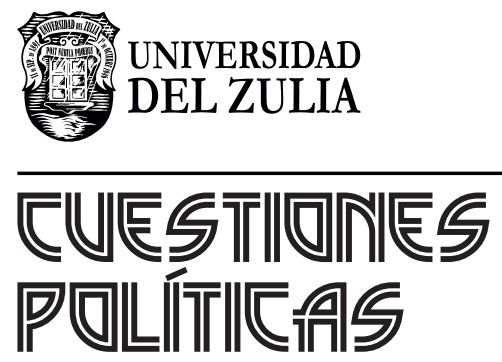

Vol. $37 \mathrm{~N}^{\circ} 64$

Esta revista fue editada en formato digital y publicada en junio de 2020, por el Fondo Editorial Serbiluz, Universidad del Zulia. Maracaibo-Venezuela 